JPE 11-1-13

\title{
Sensitivity-Based Method for the Effective Location of SSSC
}

\author{
Navid Eghtedarpour* and Ali Reza Seifi ${ }^{\dagger}$ \\ $\dagger^{*}$ School of Electrical \& Computer Engineering, Shiraz University, Iran
}

\begin{abstract}
Congestion management is one of the most challenging aspects in the recently deregulated electricity markets. FACTS devices have been shown to be an efficient alternative to control the flow of power in lines, resulting in increased loadability, lower system loss and a reduced cost of production. In this paper, the application of a static series synchronous compensator (SSSC) for the purpose of congestion management of power systems has been studied. A sensitivity-based analysis method is utilized for effective determination of the SSSC location in an electricity market. The method is topology based and it is independent of the system operation point. A power injection $\pi$-model is developed for the SSSC in this study. Numerical results based on the modified IEEE 14 bus system with/without the SSSC demonstrate the feasibility as well as the effectiveness of the SSSC for congestion management in a network. The results obtained when using the SSSC to improve system transfer capability and congestion management is encouraging.
\end{abstract}

Key Words: Congestion management, Deregulation, FACTS, SSSC

\section{INTRODUCTION}

In the deregulated electricity market, most of the time the power system operates near its rated capacity as each player in the market is trying to gain as much as possible through full utilization of the existing resources. Congestion in one or more transmission lines may occur due to a lack of coordination between generation and transmission utilities or as a result of unexpected contingencies such as generation outages, sudden increases in load demand, or failure of equipment. Therefore, congestion management is one of the key functions of any system operator ( $\mathrm{SO}$ ) in the restructured power industry.

Congestion may be prevented to some extent (preventive actions) by means of reservations, ownership rights and congestion pricing [1]-[3]. Also, congestion can be corrected by applying controls (corrective actions) such as phase shifters, tap transformers, reactive power control, re-dispatch of generation and curtailment of loads [4]-[12]. Fast relief of congestion may be possible by removing congested lines to prevent severe damages to the system, however this will diminish the stability and security margin of the system. Recently, FACTS have been introduced as a well known term for higher controllability in power systems [13]. Fast power flow control is the main application of FACTS devices, which can help a system operator to adapt a power system to varying operational conditions and to improve the usage of existing installations. Thyristorcontrolled series capacitors (TCSC) [13] and the newly devel-

\footnotetext{
Manuscript received Jun. 21, 2010; revised Oct. 31, 2010

$\dagger$ Corresponding Author: seifi@shirazu.ac.ir

Tel: +98-711-230-3081, Shiraz University

* School of electrical \& computer engineering, Shiraz University, Iran
}

oped static synchronous series compensation (SSSC) are the two main emerging FACTS devices that flexibly control line impedance and alleviate congestion.

The problem with FACTS devices is that the allocation implies the enumeration of all the possible positions among which one represents the most suitable according to a predefined objective. The definition of an opportune performance index is needed to discriminate among all the candidate locations. A considerable computational effort is required in the search for the optimal location and, for this reason; the scientific community has devoted a great deal of interest in rapidly calculated performance indexes in conjunction with efficient algorithms to find the best solution within the whole search space.

A hybrid tabu search and the simulated annealing approach are proposed to find the optimal placement of multi-type FACTS devices to minimize the total generator fuel cost in [14].

A genetic algorithm is used in [15] to simultaneously determine the suitable types of FACTS devices, their location and their ratings.

The best location is found by means of the DC load flow based economic dispatch (ED) problem in [9] which minimizes the expected thermal generation costs and the investments on the FACTS devices.

The best location in the transmission system, the type of devices and the parameters of the devices are obtained in [16] by the application of genetic algorithms.

Also [17] presents a search by genetic algorithms of the optimal locations for a number of UPFC devices. Reference 
[18] makes use of mixed integer linear programming to conduct a preliminary design study on the combinatorial optimal placement of thyristor controlled phase shifter transformers (TCPSTs) in large-scale power systems. The procedure finds the number, network location, and settings of the phase shifters that maximize system loadability under the DC load flow model, subject to the limits on the installation investment and the total number of TCPSTs.

Reference [19] presents a parallel-tabu-search based method that either maximizes the ATC with FACTS or determines the optimal allocation and parameters of the FACTS devices themselves.

In [20], an evolutionary programming (EP) method is proposed to determine the optimal allocation of FACTS devices for maximizing the total transfer capability (TTC) of power transactions between the source and the sink areas in deregulated power systems. EP simultaneously searches for FACTS locations, FACTS parameters, real power generation except for the slack bus in the source area, real power loads in the sink area, and generation bus voltages.

Reference [21] presents an optimization-based methodology to identify the key locations in the AC network where the placement of a series-connected FACTS device increases the maximum megawatt power transfer the most.

In [22] and [23] a real power flow performance index is suggested that provides a measure of severity of the line overloads for a given state of the power system. By conducting the sensitivity of the aforementioned index with respect to each FACTS device, the most sensitive lines will show the best candidates for allocation.

In [24] a genetic algorithm is used as an optimization tool to determine the location as well as the parameters of the TCSC simultaneously, while maximizing the total transfer capability, generally defined as the maximum power transfer transaction between a specific power-seller and a power-buyer within a network.

Reference [25] proposes an approach for the TCSC placement, building a sensitivity index in order to determine a branch, which should result in a placement that is the most sensitive to the largest number of contingencies. A TCSC that is in series with a chosen branch will provide the most efficient control of the system flows in the largest number of contingencies.

All of the abovementioned methods have shown superior results in the allocation of FACTS devices. A big objection to these methods is the way they treat the load pattern; usually a peak-load snapshot of the network is exploited for allocation. Although, the flow of power is not constant and changes with the load pattern during a time period. Therefore, a sensitivity based approach is exploited in this paper to overcome this drawback. Several sensitivity methods are utilized to determine the optimal locations of FACTS devices to achieve different objectives. In [26], loss sensitivity indices were used to determine the optimal placement of TCSC, thyristor-controlled phase angle regulators (TCPAR), and SVC was used to minimize the total system real power loss. In [27], a real power flow performance index (PI) was used to determine the suitable locations of TCSC and TCPAR

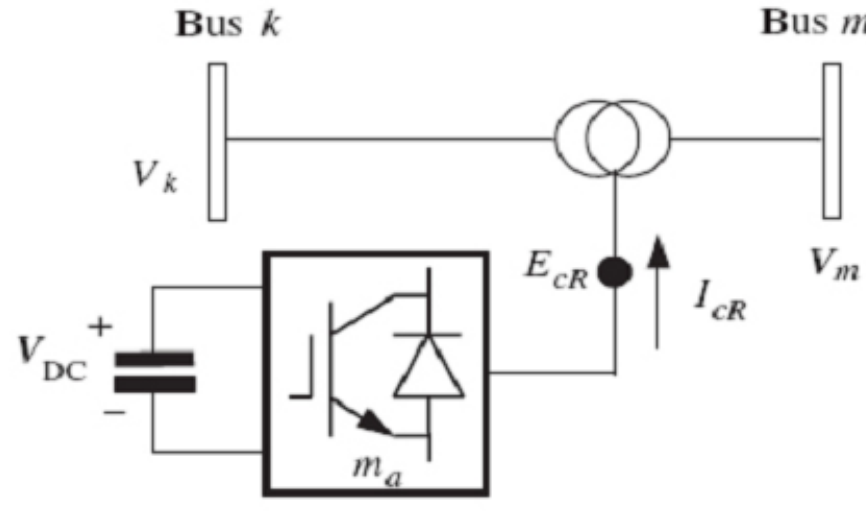

Fig. 1. Schematic diagram of SSSC connected to a transmission line.

for TTC enhancement. In [28], the RPF method combined with a sensitivity index of the loading margin to the transmission line impedances were used to determine the location of the TCSC for maximizing the TTC. However, these methods may not lead to the optimal solution because of their dependency on system topology and loading conditions. Therefore, using a sensitivity index may be restricted to local optimal solutions.

There is no, to the best of author's knowledge, paper that suggest a simple and reliable method for determining a suitable location for FACTS devices with static considerations.

A method to determine the suitable location of a SSSC, from a static point of view, has been suggested in this paper. It is based on the sensitivity with respect to the control parameters of the SSSC for the reduction of the real power flow performance index to enhance the TTC while considering system loss minimization. The method is topology based and is independent of the system operation point. A power injection $\pi$-model is developed for the SSSC in this study. The proposed algorithm has been demonstrated on a IEEE-14 Bus test system.

This paper is organized as follows. In section II a model of the SSSC is developed for sensitivity analysis. Section III deals with indices for the most effective location of the SSSC using sensitivity indices. Simulation results are presented in section V and finally, the paper is concluded in section IV.

\section{Modeling OF An SSSC}

As shown in Fig. 1, a SSSC usually consists of a coupling transformer, an inverter and a capacitor. However, a SSSC is series connected with a transmission line through the coupling transformer. The operation principle of a SSSC can be found in [29]. In principle, the inserted series voltage can be regulated to change the impedance (more precisely the reactance) of the transmission line. Therefore the power flow of the transmission line can be controlled.

The equivalent circuit of a SSSC as shown in Fig. 2 can be derived based on the operation principle of a SSSC. According to the equivalent circuit, suppose $V_{s e}=V_{s e} \angle \theta_{s e}$. The voltage of bus $i$ is taken as $\mathrm{r}$ the eference vector, $V_{i}=V_{i} \angle \theta_{i}$. The voltage source, $V_{s e}$, is the series injected voltage, and it is controllable in both its magnitudes and phase angles and is also the control variable of the SSSC. $V_{j}=V_{j} \angle \theta_{j}$ is the voltage at 


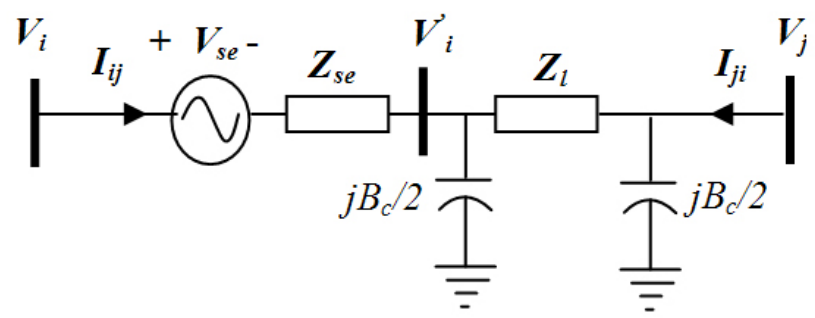

Fig. 2. Equivalent circuit of the embedded SSSC using voltage source.

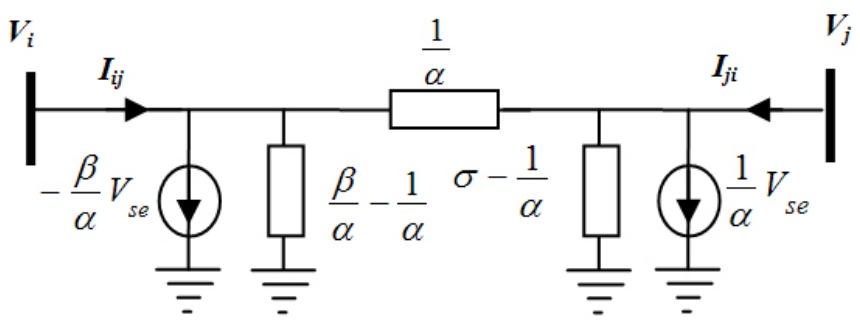

Fig. 3. Representation of the SSSC using current source.

bus $j . Z_{s e}=R_{s e}+j X_{s e}$ is the impedance of the series coupling transformer. $B_{c}$ and $Z_{l}=R_{l}+j X_{l}$ are the charging susceptance and the impedance of the line respectively. From Fig.3, the following relations hold:

$$
\begin{gathered}
V_{i}=V_{s e}+I_{i j} Z_{s e}+V_{i}^{\prime} \\
I_{i j}=\frac{V_{i}^{\prime}-V_{j}}{Z_{l}}+j \frac{B_{c}}{2} V_{i}^{\prime} \\
V_{i}^{\prime}=V_{j} \beta-I_{i j} Z_{l} \\
I_{i j}=\gamma V_{j}-\left(1+j Z_{l} \frac{B_{c}}{2}\right) I_{i j} \\
I_{i j}=\frac{\beta}{\alpha}\left(V_{i}-V_{s e}\right)-\frac{1}{\alpha} V_{j} \\
I_{i j}=\frac{1}{\alpha}\left(V_{s e}-V_{i}\right)+\sigma V_{j}
\end{gathered}
$$

where,

$$
\begin{gathered}
\alpha=j \frac{B_{c}}{2} Z_{s e} Z_{l}+Z_{l}+Z_{s e} \\
\beta=\left(1+j \frac{B_{c}}{2} Z_{l}\right) \\
\alpha=Z_{s e} \beta+Z_{l} \\
\gamma=j B_{c}-\frac{B_{c}^{2}}{4} Z_{l} .
\end{gathered}
$$

$\sigma=Z_{s e} \gamma+\beta$ Using equations (1)-(6) we can write the sending and receiving currents in terms of $V_{i}, V_{j}$ and $V_{s e}$ in a matrix form as:

$$
\left[\begin{array}{c}
I_{i j} \\
I_{j i}
\end{array}\right]=\left[\begin{array}{cc}
\frac{\beta}{\alpha} & -\frac{1}{\alpha} \\
-\frac{1}{\alpha} & \sigma
\end{array}\right]\left[\begin{array}{c}
V_{i} \\
V_{j}
\end{array}\right]+\left[\begin{array}{c}
-\frac{\beta}{\alpha} \\
\frac{1}{\alpha}
\end{array}\right] V_{s e}
$$

Eq. (7) can be presented by the equivalent circuit shown in Fig. 4.

Considering the following vectors:

$$
V_{s e}=V_{s e} \angle \theta_{s e}
$$

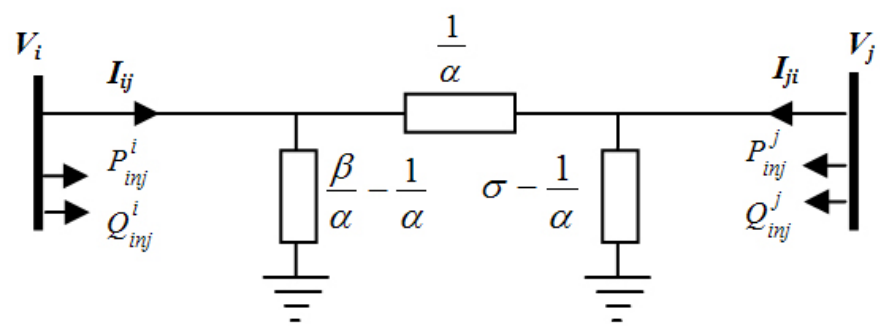

Fig. 4. The power injection $\pi$-model of embedded SSSC.

$$
\begin{gathered}
V_{i}=V_{i} \angle \theta_{i} \\
V_{j}=V_{j} \angle \theta_{j} \\
\beta=\beta \angle \theta_{\beta} .
\end{gathered}
$$

From Fig.4 the real and reactive power injections at the sending and receiving bus: $P_{i n j}^{i}, Q_{i n j}^{i}, P_{i n j}^{j}, Q_{i n j}^{i}$ can be calculated as follows:

$$
\begin{gathered}
S_{i n j}^{i *}=V_{i}^{*}\left(-\frac{\beta}{\alpha} V_{s e}\right)=-A V_{i} V_{s e} \angle\left(\theta_{s e}-\theta_{i}+\theta_{A}\right) \\
\frac{\beta}{\alpha}=A=A \angle \theta_{A} \\
P_{i n j}^{i}=-A V_{i} V_{s e} \cos \left(\theta_{s e}-\theta_{i}+\theta_{A}\right) \\
Q_{i n j}^{i}=-A V_{i} V_{s e} \sin \left(\theta_{s e}-\theta_{i}+\theta_{A}\right) \\
S_{i n j}^{j *}=V_{j}^{*}\left(\frac{1}{\alpha} V_{s e}\right)=\frac{A V_{i} V_{s e}}{\beta} \angle\left(\theta_{s e}-\theta_{j}+\theta_{A}-\theta_{\beta}\right) \\
P_{i n j}^{j}=\frac{A V_{i} V_{s e}}{\beta} \cos \left(\theta_{s e}-\theta_{j}+\theta_{A}-\theta_{\beta}\right) \\
Q_{i n j}^{j}=\frac{A V_{i} V_{s e}}{\beta} \sin \left(\theta_{s e}-\theta_{j}+\theta_{A}-\theta_{\beta}\right) \\
S_{i j}^{*}=V_{i}^{*} I_{i j}
\end{gathered}
$$

$$
P_{i j}=V_{i}^{2} A \cos \left(\theta_{A}\right)-V_{i} V_{s e} A \cos \left(\theta_{s e}-\theta_{i}+\theta_{A}\right)-
$$$$
\frac{A V_{i} V_{j}}{\beta} \cos \left(\theta_{j}-\theta_{i}+\theta_{A}-\theta_{\beta}\right)
$$

$$
\begin{aligned}
Q_{i j}= & -V_{i}^{2} A \sin \left(\theta_{A}\right)+V_{i} V_{s e} A \sin \left(\theta_{s e}-\theta_{i}+\theta_{A}\right)- \\
& \frac{A V_{i} V_{j}}{\beta} \sin \left(\theta_{j}-\theta_{i}+\theta_{A}-\theta_{\beta}\right)
\end{aligned}
$$

$P_{j i}=\sigma V_{j}^{2} A \cos \left(\theta_{\sigma}\right)+\frac{A V_{i} V_{s e}}{\beta} \cos \left(\theta_{s e}+\theta_{A}-\theta_{j}-\theta_{\beta}\right)-$

$$
\begin{aligned}
& \frac{A V_{i} V_{j}}{\beta} \cos \left(\theta_{i}+\theta_{A}-\theta_{j}-\theta_{\beta}\right) \\
Q_{j i}= & -\sigma V_{j}^{2} A \sin \left(\theta_{\sigma}\right)-\frac{A V_{i} V_{s e}}{\beta} \sin \left(\theta_{s e}+\theta_{A}-\theta_{j}-\theta_{\beta}\right)+ \\
& \frac{A V_{i} V_{j}}{\beta} \sin \left(\theta_{i}+\theta_{A}-\theta_{j}-\theta_{\beta}\right) .
\end{aligned}
$$


The power injection $\pi$-model of the embedded SSSC is shown in Fig. 4. In this model the resistance of the transmission line and the SSSC coupling transformer are considered, therefore the total power loss can be calculated accurately as:

$$
\begin{aligned}
P_{\text {loss }} & =P_{i j}+P_{j i}=V_{i}^{2} A \cos \left(\theta_{A}\right)+\sigma V_{j}^{2} \cos \left(\theta_{\sigma}\right) \\
& -V_{i} V_{s e} A \cos \left(\theta_{A}-\theta_{i}^{\prime}\right) \\
& +\frac{A V_{j} V_{s e}}{\beta} \cos \left(\theta_{A}-\theta_{\beta}-\theta_{i}^{\prime}+\theta_{i j}\right) \\
& -\frac{2 A V_{j} V_{i}}{\beta} \cos \left(-\theta_{i j}+\theta_{A}-\theta_{\beta}\right) .
\end{aligned}
$$

Where,

$$
\begin{gathered}
\theta_{i}^{\prime}=\theta_{i}-\theta_{s e} \\
\theta_{i j}=\theta_{i}-\theta_{j} .
\end{gathered}
$$

\section{EFFECTIVE Location OF THE SSSC USING SENSITIVITY INDICES}

In the past, most of the works have utilized dynamic considerations for the placement of the FACTS devices, as these devices were utilized mainly to improve the stability of the power system networks. In the present work, the FACTS devices have been considered from a static point of view to reduce the total system real power transmission loss $\left(P_{\text {loss }}\right)$. Hence, a new method based on the sensitivity approach, as described below, has been suggested for placement of the FACTS devices.

\section{A. Loss Sensitivity Indices}

This section proposes a method based on the sensitivity of the total transmission loss $\left(P_{L}\right)$ with respect to the control parameter of the SSSC for its best placement. The control parameter for the SSSC is the phase angle shift $\left(\theta_{k}\right.$ placed in line- $k$ ). Thus, the loss sensitivity factor with respect to this parameter can be defined as:

$a_{k}=\frac{\partial P_{\text {loss }}}{\partial \theta_{i j}}=\begin{gathered}\text { Loss sensitivity with respect to SSSC } \\ \text { placed in line }-k(k=1, \ldots, N)\end{gathered}$

This factor can be computed at a base load flow solution as given below.

Consider a line $\mathrm{k}$ connected between bus $i$ and bus $j$ and having a series impedance $R_{l}+j X_{l} . X_{l}$ is the net reactance considering the reactance of the series compensator, if present, in the line. Let the complex voltages at the buses $i$ and $j$ be $V_{i}=V_{i} \angle \theta_{i}$ and $V_{j}=V_{j} \angle \theta_{j}$ respectively. $\theta_{i j}$ is the net phase shift in the line $\mathrm{k}$ including the effect of the SSSC.

$$
\begin{aligned}
a_{k}=\frac{\partial P_{\text {loss }}}{\partial \theta_{i j}}= & -\frac{A V_{j} V_{\text {se }}}{\beta} \sin \left(\theta_{A}-\theta_{\beta}-\theta_{i}^{\prime}+\theta_{i j}\right) \\
& +\frac{2 A V_{j} V_{i}}{\beta} \cos \left(\theta_{A}-\theta_{\beta}\right) \sin \left(\theta_{i j}\right) .
\end{aligned}
$$

\section{B. Real Power Flow Performance Index Sensitivity Indices}

The severity of the system loading under normal and contingency cases can be described by a real power line flow performance index [30], as given below:

$$
P I=\sum_{m=1}^{N_{L}} \frac{W_{m}}{2 n}\left(\frac{P_{L m}}{P_{L}^{\max }}\right)^{2 n}
$$

where $P_{L m}$ is the real power flow, $P_{L}^{\max }$ is the rated capacity of line- $\mathrm{m}, \mathrm{n}$ is the exponent and wm a real nonnegative weighting coefficient which may be used to reflect the importance of the lines.

PI will be small when all of the lines are within their limits and it will reach a high value when there are overloads. Thus, it provides a good measure of the severity of the line overloads for a given state of the power system. Most of the works on contingency selection algorithms utilize the second order performance indices which, in general, suffer from masking effects. The lack of discrimination, in which the performance index for a case with many small violations may be comparable in value to the index for a case with one huge violation, is known as a masking effect [30]. By most operational standards, the system with one huge violation is much more severe than a system with many small violations. The masking effect to some extent can be avoided by using higher order performance indices in which $n>1$. However, in this study, the value of the exponent has been taken as 2 and $w_{i}=1$.

The real power flow PI sensitivity factors with respect to the parameters of the SSSC can be defined as:

$b_{k}=\left.\frac{\partial P I}{\partial \theta_{s e}}\right|_{\theta_{s e}=0}=$ PI sensitivity with respect to. SSSC

The sensitivity of the PI with respect to the SSSC parameter connected between the bus-i and the bus- $j$ can be written as:

$$
\frac{\partial P I}{\partial \theta_{s e}}=\sum_{m=1}^{N_{L}} W_{m} P_{L m}^{3}\left(\frac{1}{P_{L}^{\max }}\right)^{4 n} \frac{\partial P_{L m}}{\partial \theta_{s e}} .
$$

The real power flow in line-m can be represented in terms of the real power injections using the DC power flow equations [17] where $s$ is the slack bus, as:

$$
P_{L m}= \begin{cases}\sum_{\substack{n=1 \\ n \neq s}}^{N} S_{m n} P_{n} & \text { for } m \neq k \\ \sum_{\substack{n=1 \\ n \neq s}}^{N} S_{m n} P_{n}+P_{j} & \text { for } m=k\end{cases}
$$

Using equation (21), the following relationship can be derived:

$$
\frac{\partial P_{L m}}{\partial \theta_{s e}}= \begin{cases}\left(S_{m i} \frac{\partial P_{i}}{\partial \theta_{s e}}+S_{m j} \frac{\partial P_{j}}{\partial \theta_{s e}}\right) & \text { for } m \neq k \\ \left(S_{m i} \frac{\partial P_{i}}{\partial \theta_{s e}}+S_{m j} \frac{\partial P_{j}}{\partial \theta_{s e}}\right)+\frac{\partial P_{j}}{\partial \theta_{s e}} & \text { for } m \neq k\end{cases}
$$




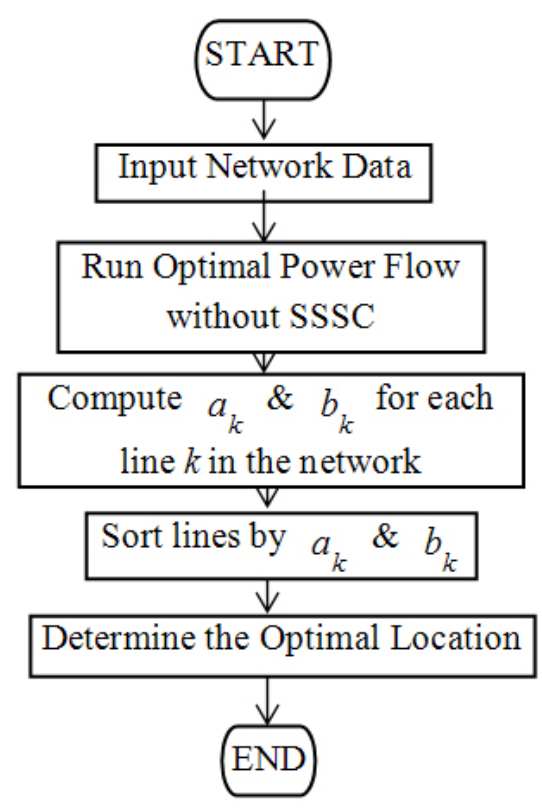

Fig. 5. Flowchart for the proposed method in effective location of SSSC.

The terms $\left.\frac{\partial P_{i}}{\partial \theta_{s e}}\right|_{\theta_{s e}=0}$ and $\left.\frac{\partial P_{j}}{\partial \theta_{s e}}\right|_{\theta_{s e}=0}$ can be derived as below:

$$
\begin{gathered}
\left.\frac{\partial P_{i}}{\partial \theta_{s e}}\right|_{\theta_{s e}=0}=\left.\frac{\partial P_{i n j}^{i}}{\partial \theta_{s e}}\right|_{\theta_{s e}=0}=\left.V_{i} V_{s e} A \sin \left(\theta_{A}-\theta_{i}^{\prime}\right)\right|_{\theta_{s e}=0} \\
=V_{i} V_{s e} A \sin \left(\theta_{A}-\theta_{i}\right) \\
\left.\frac{\partial P_{j}}{\partial \theta_{s e}}\right|_{\theta_{s e}=0}=\left.\frac{\partial P_{i n j}^{j}}{\partial \theta_{s e}}\right|_{\theta_{s e}=0}=-\frac{V_{j} V_{s e} A}{\beta} \sin \left(\theta_{i j}+\theta_{A}-\theta_{\beta}\right)
\end{gathered}
$$

\section{Criteria for the best location}

The best place for the FACTS device is the most sensitive line. With the sensitivity indices computed for the SSSC, the following criteria can be used for its effective placement.

a) In the power loss reduction method the SSSC should be placed in a line having the most positive loss sensitivity index.

b) In the PI method the SSSC should be placed in a line having most negative sensitivity index.

The procedure is shown in Fig.5.

\section{Simulation Results}

In this study, a 14-bus IEEE test system has been studied to investigate the result of the proposed method in the placement of a SSSC. A single line diagram of the studied network is shown in Fig. 6.

The result of the OPF run on the test network is shown in Table I. From the OPF, it was found that the real power flow in lines 1 and 10 were 1.077 and 1.053 pu respectively, which are more than the lines loading limits.

The sensitivities of the real power loss reduction and the real power flow performance indices with respect to the SSSC control parameter have been computed and are shown in Tables II-IV. To confirm the validity of the indices in the operation range of the SSSC, the indices are calculated for
TABLE I

OPF RUN RESULT WITHOUT SSSC

\begin{tabular}{|c|c|c|c|}
\hline Line \# & Bus i & Bus j & Loading\% \\
\hline $\mathbf{1}$ & 1 & 2 & $\mathbf{1 . 0 7 7}$ \\
\hline $\mathbf{2}$ & 1 & 5 & 0.794 \\
\hline $\mathbf{3}$ & 2 & 3 & 0.883 \\
\hline $\mathbf{4}$ & 2 & 4 & 0.735 \\
\hline $\mathbf{5}$ & 2 & 5 & 0.446 \\
\hline $\mathbf{6}$ & 3 & 4 & 0.501 \\
\hline $\mathbf{7}$ & 4 & 5 & 0.807 \\
\hline $\mathbf{8}$ & 4 & 7 & 0.727 \\
\hline $\mathbf{9}$ & 4 & 9 & 0.469 \\
\hline $\mathbf{1 0}$ & 5 & 6 & $\mathbf{1 . 0 5 3}$ \\
\hline $\mathbf{1 1}$ & 6 & 11 & 0.288 \\
\hline $\mathbf{1 2}$ & 6 & 12 & 0.275 \\
\hline $\mathbf{1 3}$ & 6 & 13 & 0.647 \\
\hline $\mathbf{1 4}$ & 7 & 8 & 0.179 \\
\hline $\mathbf{1 5}$ & 7 & 9 & 0.997 \\
\hline $\mathbf{1 6}$ & 9 & 10 & 0.207 \\
\hline $\mathbf{1 7}$ & 9 & 14 & 0.654 \\
\hline $\mathbf{1 8}$ & 10 & 11 & 0.304 \\
\hline $\mathbf{1 9}$ & 12 & 13 & 0.124 \\
\hline $\mathbf{2 0}$ & 13 & 14 & 0.413 \\
\hline & & & \\
\hline
\end{tabular}

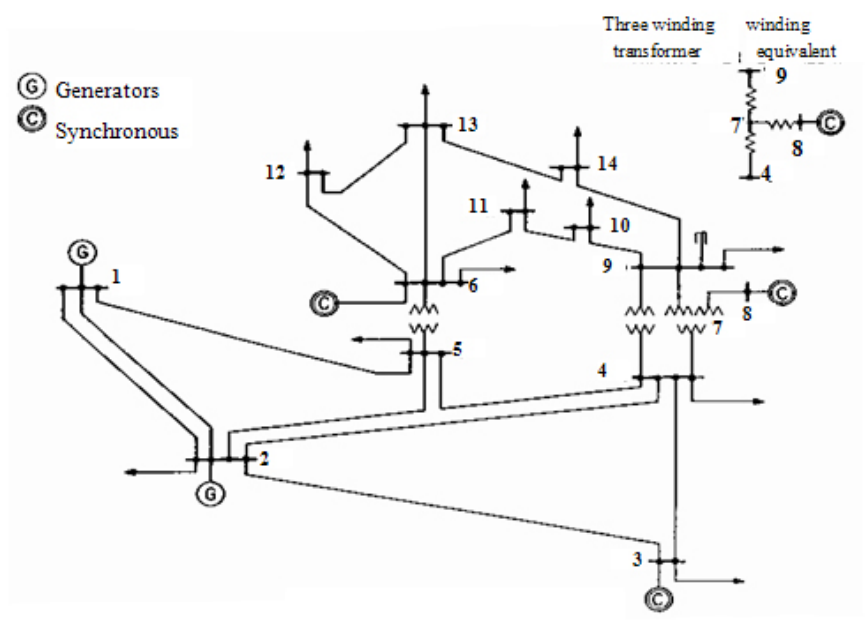

Fig. 6. 14-bus IEEE test system.

different magnitudes and phase shifts. The most sensitive line in each case is presented in bold type. According to the criteria for effective allocation of FACTS, it can be observed from Table II that the best choice for the SSSC location considering the TTC would be L\#7 between buses 4 and 5. Comparing the result with the minimum loss index in Tables III and IV, it is observed that the best location for the minimum system loss would be the L\#1 in the first stage and then L\#7. Therefore, L\#7 is chosen as an effective location for the SSSC installation.

\section{CONCLUSION}

This paper employs a sensitivity-based analysis method for effective determination of the SSSC location in a power system planning problem. A power injection $\pi$-model is developed for the SSSC, and then the loss and the real power flow performance sensitivity indices are modified for the networks containing a SSSC. Based on these two indices, the best point is selected for the SSSC location. It shows a high computational efficiency. The proposed method is topology based and is independent of system operation. 
TABLE II

$b_{k}$ CALCULATED FOR DIFFERENT MAGNITUDES OF $V_{s e}$

\begin{tabular}{|c|c|c|c|c|c|c|c|c|c|c|c|}
\hline line $V_{s e}$ & 0.00 & 0.01 & 0.02 & 0.03 & 0.04 & 0.05 & 0.06 & 0.07 & 0.08 & 0.09 & 0.10 \\
\hline L \#1 & 0.000 & -0.002 & -0.004 & -0.006 & -0.008 & -0.010 & -0.012 & -0.014 & -0.017 & -0.019 & -0.021 \\
\hline $\mathrm{L} \# 2$ & 0.000 & -0.002 & -0.005 & -0.007 & -0.009 & -0.011 & -0.014 & -0.016 & -0.018 & -0.021 & -0.023 \\
\hline $\mathrm{L} \# \mathbf{3}$ & 0.000 & -0.002 & -0.004 & -0.006 & -0.009 & -0.011 & -0.013 & -0.015 & -0.017 & -0.019 & -0.021 \\
\hline $\mathrm{L} \# 4$ & 0.000 & -0.002 & -0.005 & -0.007 & -0.009 & -0.011 & -0.014 & -0.016 & -0.018 & -0.020 & -0.023 \\
\hline $\mathrm{L} \# 5$ & 0.000 & -0.002 & -0.005 & -0.007 & -0.010 & -0.012 & -0.015 & -0.017 & -0.019 & -0.022 & -0.024 \\
\hline $\mathrm{L} \# 6$ & 0.000 & -0.003 & -0.005 & -0.008 & -0.010 & -0.013 & -0.015 & -0.018 & -0.021 & -0.023 & -0.026 \\
\hline $\mathrm{L} \# 7$ & 0.000 & -0.003 & -0.006 & -0.009 & -0.011 & -0.014 & -0.017 & -0.020 & -0.023 & -0.026 & -0.029 \\
\hline $\mathrm{L} \# 8$ & 0.000 & -0.002 & -0.004 & -0.006 & -0.008 & -0.010 & -0.013 & -0.015 & -0.017 & -0.019 & -0.021 \\
\hline L \#9 & 0.000 & -0.002 & -0.005 & -0.007 & -0.010 & -0.012 & -0.014 & -0.017 & -0.019 & -0.022 & -0.024 \\
\hline $\mathrm{L} \# 10$ & 0.000 & -0.002 & -0.004 & -0.006 & -0.008 & -0.010 & -0.011 & -0.013 & -0.015 & -0.017 & -0.019 \\
\hline L \#11 & 0.000 & -0.002 & -0.005 & -0.007 & -0.010 & -0.012 & -0.015 & -0.017 & -0.019 & -0.022 & -0.024 \\
\hline $\mathrm{L} \# 12$ & 0.000 & -0.002 & -0.005 & -0.007 & -0.010 & -0.012 & -0.015 & -0.017 & -0.019 & -0.022 & -0.024 \\
\hline $\mathrm{L} \# 13$ & 0.000 & -0.002 & -0.004 & -0.007 & -0.009 & -0.011 & -0.013 & -0.015 & -0.018 & -0.020 & -0.022 \\
\hline L \#14 & 0.000 & -0.002 & -0.005 & -0.007 & -0.010 & -0.012 & -0.015 & -0.017 & -0.020 & -0.022 & -0.025 \\
\hline $\mathrm{L} \# 15$ & 0.000 & -0.001 & -0.002 & -0.003 & -0.004 & -0.006 & -0.007 & -0.008 & -0.009 & -0.010 & -0.011 \\
\hline $\mathrm{L} \# 16$ & 0.000 & -0.002 & -0.005 & -0.007 & -0.010 & -0.012 & -0.015 & -0.017 & -0.020 & -0.022 & -0.024 \\
\hline $\mathrm{L} \# 17$ & 0.000 & -0.002 & -0.004 & -0.006 & -0.008 & -0.010 & -0.013 & -0.015 & -0.017 & -0.019 & -0.021 \\
\hline L \#18 & 0.000 & -0.002 & -0.005 & -0.007 & -0.010 & -0.012 & -0.015 & -0.017 & -0.020 & -0.022 & -0.025 \\
\hline L \#19 & 0.000 & -0.002 & -0.005 & -0.007 & -0.010 & -0.012 & -0.015 & -0.017 & -0.020 & -0.022 & -0.024 \\
\hline $\mathrm{L} \# 20$ & 0.000 & -0.002 & -0.005 & -0.007 & -0.010 & -0.012 & -0.014 & -0.017 & -0.019 & -0.021 & -0.024 \\
\hline
\end{tabular}

TABLE III

$a_{k}$ CALCULATED FOR DIFFERENT VALUES OF SSSC PHASE SHIFT $\theta_{s e}$

\begin{tabular}{|c|c|c|c|c|c|c|c|c|c|c|c|c|c|c|c|c|}
\hline $\begin{array}{l}\theta_{\text {se }}(\operatorname{deg}) \\
\text { line }\end{array}$ & 0 & 1 & 2 & 3 & 4 & 5 & 6 & 7 & 8 & 9 & 10 & 11 & 12 & 13 & 14 & 15 \\
\hline L \#1 & 0.594 & 0.596 & 0.597 & 0.598 & 0.599 & 0.600 & 0.601 & 0.601 & 0.602 & 0.602 & 0.602 & 0.602 & 0.602 & 0.601 & 0.601 & 0.600 \\
\hline $\mathrm{L} \# 2$ & 0.380 & 0.381 & 0.382 & 0.383 & 0.385 & 0.386 & 0.386 & 0.387 & 0.388 & 0.389 & 0.389 & 0.390 & 0.390 & 0.390 & 0.390 & 0.391 \\
\hline $\mathrm{L} \# 3$ & 0.387 & 0.387 & 0.388 & 0.389 & 0.390 & 0.390 & 0.391 & 0.391 & 0.391 & 0.391 & 0.391 & 0.391 & 0.391 & 0.391 & 0.391 & 0.390 \\
\hline $\mathrm{L} \# 4$ & 0.406 & 0.407 & 0.408 & 0.409 & 0.410 & 0.411 & 0.411 & 0.412 & 0.412 & 0.412 & 0.412 & 0.412 & 0.412 & 0.412 & 0.412 & 0.412 \\
\hline $\mathrm{L} \# 5$ & 0.384 & 0.385 & 0.385 & 0.386 & 0.387 & 0.387 & 0.388 & 0.388 & 0.388 & 0.388 & 0.388 & 0.388 & 0.388 & 0.388 & 0.388 & 0.387 \\
\hline $\mathrm{L} \# 6$ & 0.281 & 0.281 & 0.281 & 0.280 & 0.280 & 0.280 & 0.279 & 0.279 & 0.278 & 0.277 & 0.277 & 0.276 & 0.275 & 0.274 & 0.272 & 0.271 \\
\hline $\mathrm{L} \# 7$ & 0.533 & 0.532 & 0.531 & 0.530 & 0.528 & 0.527 & 0.525 & 0.523 & 0.521 & 0.519 & 0.516 & 0.514 & 0.511 & 0.508 & 0.505 & 0.502 \\
\hline $\mathrm{L} \# 8$ & 0.300 & 0.299 & 0.298 & 0.298 & 0.297 & 0.296 & 0.295 & 0.294 & 0.292 & 0.291 & 0.290 & 0.288 & 0.287 & 0.285 & 0.283 & 0.281 \\
\hline $\mathrm{L} \# 9$ & 0.150 & 0.150 & 0.150 & 0.149 & 0.149 & 0.148 & 0.148 & 0.148 & 0.147 & 0.146 & 0.146 & 0.145 & 0.144 & 0.144 & 0.143 & 0.142 \\
\hline $\mathrm{L} \# 10$ & 0.272 & 0.272 & 0.272 & 0.271 & 0.271 & 0.270 & 0.270 & 0.269 & 0.268 & 0.267 & 0.266 & 0.265 & 0.264 & 0.263 & 0.262 & 0.260 \\
\hline L \#11 & 0.313 & 0.314 & 0.314 & 0.314 & 0.314 & 0.314 & 0.314 & 0.314 & 0.314 & 0.313 & 0.313 & 0.312 & 0.312 & 0.311 & 0.310 & 0.309 \\
\hline $\mathrm{L} \# 12$ & 0.275 & 0.275 & 0.275 & 0.276 & 0.276 & 0.276 & 0.276 & 0.276 & 0.276 & 0.276 & 0.276 & 0.275 & 0.275 & 0.275 & 0.274 & 0.273 \\
\hline L \#13 & 0.405 & 0.405 & 0.405 & 0.405 & 0.405 & 0.405 & 0.405 & 0.404 & 0.404 & 0.403 & 0.403 & 0.402 & 0.401 & 0.400 & 0.399 & 0.397 \\
\hline L \#14 & 0.328 & 0.327 & 0.326 & 0.324 & 0.323 & 0.321 & 0.320 & 0.318 & 0.316 & 0.314 & 0.312 & 0.310 & 0.307 & 0.305 & 0.303 & 0.300 \\
\hline L \#15 & 0.414 & 0.413 & 0.412 & 0.411 & 0.409 & 0.407 & 0.406 & 0.404 & 0.402 & 0.399 & 0.397 & 0.395 & 0.392 & 0.390 & 0.387 & 0.384 \\
\hline L \#16 & 0.460 & 0.460 & 0.459 & 0.458 & 0.457 & 0.456 & 0.455 & 0.453 & 0.452 & 0.450 & 0.448 & 0.446 & 0.444 & 0.442 & 0.439 & 0.437 \\
\hline L \#17 & 0.266 & 0.266 & 0.266 & 0.267 & 0.267 & 0.267 & 0.267 & 0.267 & 0.267 & 0.267 & 0.266 & 0.266 & 0.266 & 0.265 & 0.265 & 0.264 \\
\hline $\mathrm{L} \# 18$ & 0.297 & 0.297 & 0.297 & 0.296 & 0.296 & 0.296 & 0.296 & 0.295 & 0.294 & 0.294 & 0.293 & 0.292 & 0.291 & 0.290 & 0.289 & 0.288 \\
\hline L \#19 & 0.244 & 0.245 & 0.247 & 0.248 & 0.249 & 0.251 & 0.252 & 0.253 & 0.254 & 0.255 & 0.256 & 0.256 & 0.257 & 0.258 & 0.258 & 0.259 \\
\hline $\mathrm{L} \# 20$ & 0.218 & 0.218 & 0.218 & 0.219 & 0.219 & 0.219 & 0.219 & 0.219 & 0.219 & 0.219 & 0.219 & 0.219 & 0.219 & 0.218 & 0.218 & 0.218 \\
\hline
\end{tabular}

TABLE IV

$a_{k}$ CALCULATED FOR DIFFERENT MAGNITUDES OF $V_{s e}$

\begin{tabular}{|c|c|c|c|c|c|c|c|c|c|c|c|}
\hline line $V_{s e}$ & 0 & 0.01 & 0.02 & 0.03 & 0.04 & 0.05 & 0.06 & 0.07 & 0.08 & 0.09 & 0.1 \\
\hline L \#1 & 0.082 & 0.134 & 0.186 & 0.237 & 0.289 & 0.341 & 0.393 & 0.445 & 0.496 & 0.548 & 0.600 \\
\hline $\mathrm{L} \# 2$ & 0.113 & 0.141 & 0.169 & 0.196 & 0.224 & 0.252 & 0.280 & 0.307 & 0.335 & 0.363 & 0.391 \\
\hline $\mathrm{L} \# \mathbf{3}$ & 0.094 & 0.124 & 0.153 & 0.183 & 0.213 & 0.242 & 0.272 & 0.302 & 0.331 & 0.361 & 0.390 \\
\hline $\mathrm{L} \# 4$ & 0.097 & 0.128 & 0.160 & 0.191 & 0.223 & 0.254 & 0.286 & 0.317 & 0.349 & 0.380 & 0.412 \\
\hline $\mathrm{L} \# \mathbf{5}$ & 0.069 & 0.101 & 0.133 & 0.165 & 0.196 & 0.228 & 0.260 & 0.292 & 0.324 & 0.355 & 0.387 \\
\hline $\mathrm{L} \# 6$ & -0.038 & -0.007 & 0.024 & 0.055 & 0.086 & 0.116 & 0.147 & 0.178 & 0.209 & 0.240 & 0.271 \\
\hline $\mathrm{L} \# 7$ & -0.021 & 0.031 & 0.083 & 0.136 & 0.188 & 0.240 & 0.293 & 0.345 & 0.397 & 0.449 & 0.502 \\
\hline $\mathrm{L} \# 8$ & 0.001 & 0.029 & 0.057 & 0.085 & 0.113 & 0.141 & 0.169 & 0.197 & 0.225 & 0.253 & 0.281 \\
\hline $\mathrm{L} \# 9$ & 0.001 & 0.015 & 0.029 & 0.043 & 0.057 & 0.071 & 0.085 & 0.100 & 0.114 & 0.128 & 0.142 \\
\hline $\mathrm{L} \# 10$ & 0.002 & 0.028 & 0.054 & 0.080 & 0.106 & 0.131 & 0.157 & 0.183 & 0.209 & 0.235 & 0.260 \\
\hline L \#11 & 0.018 & 0.047 & 0.076 & 0.105 & 0.134 & 0.163 & 0.193 & 0.222 & 0.251 & 0.280 & 0.309 \\
\hline $\mathrm{L} \# 12$ & 0.024 & 0.049 & 0.074 & 0.099 & 0.124 & 0.149 & 0.174 & 0.199 & 0.224 & 0.249 & 0.273 \\
\hline $\mathrm{L} \# 13$ & 0.032 & 0.069 & 0.105 & 0.142 & 0.178 & 0.215 & 0.251 & 0.288 & 0.324 & 0.361 & 0.397 \\
\hline L \#14 & -0.001 & 0.029 & 0.060 & 0.090 & 0.120 & 0.150 & 0.180 & 0.210 & 0.240 & 0.270 & 0.300 \\
\hline $\mathrm{L} \# 15$ & 0.002 & 0.040 & 0.078 & 0.117 & 0.155 & 0.193 & 0.231 & 0.269 & 0.308 & 0.346 & 0.384 \\
\hline $\mathrm{L} \# 16$ & 0.004 & 0.047 & 0.091 & 0.134 & 0.177 & 0.220 & 0.264 & 0.307 & 0.350 & 0.393 & 0.437 \\
\hline $\mathrm{L} \# 17$ & 0.029 & 0.053 & 0.076 & 0.099 & 0.123 & 0.146 & 0.170 & 0.193 & 0.217 & 0.240 & 0.264 \\
\hline $\mathrm{L} \# 18$ & -0.009 & 0.021 & 0.051 & 0.080 & 0.110 & 0.140 & 0.169 & 0.199 & 0.228 & 0.258 & 0.288 \\
\hline L \#19 & 0.004 & 0.030 & 0.055 & 0.080 & 0.106 & 0.131 & 0.157 & 0.182 & 0.208 & 0.233 & 0.259 \\
\hline L \#20 & 0.022 & 0.041 & 0.061 & 0.080 & 0.100 & 0.120 & 0.139 & 0.159 & 0.178 & 0.198 & 0.218 \\
\hline
\end{tabular}




\section{REFERENCES}

[1] M. Alomoush and M. Shahidehpour, "Contingency constrained congestion management with a minimum number of adjustments in preferred schedules," Electric Power and Energy Systems, Vol. 22, pp. 277-290, Mar. 2000.

[2] Stoft S, "Transmission pricing zones: simple or complex?," The Electricity Journal, Vol. 10, No. 1, pp. 24-31, Feb. 1997.

[3] Shirmohammadi D, Wollenberg B, Vojdani A, Sandrin P, "Transmission dispatch and congestion management in the emerging energy market structures," IEEE Transactions on Power Systems, Vol. 13, No. pp. 146674, Nov. 1998.

[4] Gedra T, "On transmission congestion and pricing," IEEE Transactions on Power Systems, Vol. 14, No. 1, pp. 241-8, Feb. 1999.

[5] Abdul-Rahman K, Shahidehpour M, "A practical power systems resource scheduling with OPF constraints," IEEE Transactions on Power Systems, Vol. 11, No. 1, pp. 254-9, Feb. 1996.

[6] Deeb N, Shahidehpour M., "Improved system operation by optimal adjustment of reactive generation in electric power network, "International Journal of Energy Research, Vol. 14, No. 1, pp. 651-64, Mar. 1990.

[7] Abdul-Rahman K, Shahidehpour M., "A fuzzy-based optimal reactive power control," IEEE Transactions on Power Systems, Vol. 8, No. 2, pp. 662-70, May 1993.

[8] Deeb N, Shahidehpour M., "Cross decomposition for multi-area optimal reactive power planning," IEEE Transactions on Power Systems, Vol. 8, No. 4, pp. 1539-44, Nov. 1993.

[9] Tong S, Shahidehpour M., "An overview of power generation scheduling in the optimal operation of a large scale power system," Electric Machines and Power Systems, Vol. 19, No. 5, pp.731-62, Nov. 1991.

[10] Deeb N, Shahidehpour M., "Application of Newton's optimal power flow in voltage/reactive power control," IEEE Transactions on Power Systems, Vol. 5, No. 4, pp. 1454, Nov. 1990.

[11] Wang C, Shahidehpour M, Adapa R., "Optimal power generation scheduling," Proceedings of the American Power Conference, Apr. 1993.

[12] Abdul-Rahman K, Shahidehpour M., "Application of fuzzy sets to optimal reactive power planning with security constraints," IEEE Transactions on Power Systems, Vol. 9, No. 2, pp. 589-97, May 1994.

[13] M. Gitizadeh, M. Kalantar, "FACTS devices allocation to congestion alleviation incorporating voltage dependence of loads," Iranian Journal of Electrical \& Electronic Engineering, Vol. 4, No. 4, pp. 176-190, Oct. 2008.

[14] P. Bhasaputra and placeW. Ongsakul, "Optimal placement of multi-type facts devices by hybrid ts/sa approach," In Proc. 2003 of Circuita and Systems Int. Symp., pp III-375- III-378, 2003.

[15] L.J. Cai, I. Erlich, G. Stamtsis, "Optimal choice and allocation of FACTS devices in deregulated electricity market using genetic algorithms," In Proc. 2004 of Power Systems Conf., pp. 201-207, 2004.

[16] S. Gerbex, R. Cherkaoui, A. J. Germond, "Optimal location of multitype FACTS devices in a power system by means of genetic algorithms," IEEE Trans. Power Systems, Vol. 16, No. 3, pp. 537-544, Aug. 2001.

[17] H. C. Leung, T. S. Chung, "Optimal placement of FACTS controller in power system by a genetic-based algorithm," In Proc. 1999 IEEE Power Electronics and Drive Systems Conf., pp.833-836, 1999.

[18] F. G. M. Lima, F. D. Galiana, I. Kockar, J. Munoz, "Phase shifter placement in large-scale systems via mixed integer linear programming," IEEE Trans. Power Systems, Vol. 18, No. 3, pp. 1029- 1034, Aug. 2003.

[19] Hiroyuki Mori, Yuichiro Goto, "A parallel tabu search based method for determining optimal allocation of FACTS in power systems," In Proc. 2000 of PowerCon Conf., pp. 1077-1082, 2000.
[20] W. Ongsakul, P. Jirapong, "Optimal allocation of FACTS devices to enhance total transfer capability using evolutionary programming," In Proc. 2005 of Circuits and Systems Int. Symp., pp. 4175-4178, 2005.

[21] T. Orfanogianni, R. Bacher, "Steady-state optimization in power systems with series FACTS devices," IEEE Trans. Power Systems, Vol. 18, No. 1, pp. 19-26, Feb. 2003.

[22] S.N. Singh and A.K. David, "A new approach for placement of FACTS devices in open power markets," IEEE Power Engineering Review, pp. 60-58, Sep. 2001.

[23] S.N. Singh and A.K. David, "Placement of facts devices in open power market," In Proc. 2000 IEEE Advances in Power System Control, Operation and Management Conf., pp.173-177, 2000.

[24] W. Feng, G. B. Shrestha, "Allocation of TCSC devices to optimize total transmission capacity in a competitive power market," In Proc. 2001 of Power Engineering Sociecty Wint. Meet., pp. 587 - 593, 2001.

[25] Y. Lu, A. Abur, "Improving system static security via optimal placement of thyristor controlled series capacitors (TCSC)," In Proc. 2001 of Power Engineering Sociecty Wint. Meet., pp. 516 - 521, 2001.

[26] Preedavichit, P. and Srivastava, S.C., "Optimal reactive power dispatch considering FACTS devices," Electric Power Systems Research, Vol. 46, No. 3, pp. 251-257, Sep. 1998.

[27] Verma, K.S.; Singh, S.N.; and Gupta, H.O., "FACTS devices location for enhancement of total transfer capability," Proceedings of the IEEE Power Engineering Society Winter Meeting, Jan./Feb. 2001.

[28] Leonidaki, E.A., Hatziargyriou, StateN.D., Manos, G.A., and Papadias, B.C., "A systematic approach for effective location of series compensation to increase available transfer capability," Proceedings of the IEEE Porto Power Tech, Sep. 2001.

[29] L. Gyugyi, C.D. Shauder, and K.K. Sen, "Static synchronous series compensator: a solid-state approach to the series compensation of transmission lines," IEEE Transactions on Power Delivery, Vol.12, No.1, pp. 406-413, Jan. 1997.

[30] G.C. Ejebe and B.F. Wollenberg, "Automatic contingency selection," IEEE Trans. on Power Apparatus and Systems, Vol. 98, No. 1, pp. 92104, Jan./Feb. 1979.

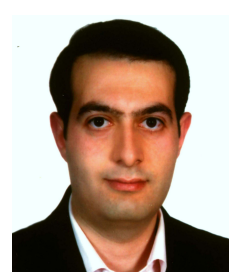

Navid Eghtedarpour was born in Shiraz, Iran in 1981 $\mathrm{He}$ received his B.S. and M.S. in Electrical Engineering from Shiraz University, Shiraz, Iran, in 2003 and 2006, respectively. $\mathrm{He}$ is currently pursuing his $\mathrm{Ph} . \mathrm{D}$. in the School of Electrical and Computer Engineering, Shiraz University. His research interests include power quality and the application of FACTS in power systems.

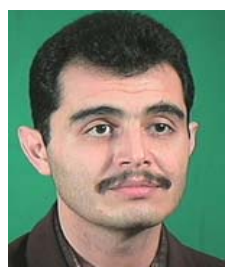

Ali Reza Seifi was born in Shiraz, Iran, on August 9, 1968. He received his B.S. in Electrical Engineering from Shiraz University, Shiraz, Iran, in 1991, his M.S. in Electrical Engineering from the University of Tabriz, Tabriz, Iran, in 1993 and his Ph.D. in Electrical Engineering from Tarbiat Modarres University (T.M.U.), Tehran, Iran, in 2001. He is currently an Associate Professor in Department of Power and Control Engineering, School of Electrical and Computer Engineering, Shiraz University, Shiraz, Iran. His research interests include power plant simulations, power systems, electrical machine simulations, power electronics and fuzzy optimization. 